\title{
QUALIDADE NA PERCEPÇÃO DISCENTE DO CURSO DE CIÊNCIAS CONTÁBEIS NA UNEMAT DE TANGARÁ DA SERRA
}

\author{
Alexandro da Matta Sanches ${ }^{1}$ \\ Karine Medeiros Anunciato ${ }^{2}$ \\ Cleiton Franco ${ }^{3}$ \\ Marcelo Evandro Alves ${ }^{4}$
}

\section{RESUMO}

Praticar serviços de qualidade constitui-se uma das principais estratégias de sobrevivência das Instituições de Ensino Superior (IES) no concorrido mercado educacional. O grande desafio dos gestores é entender e identificar o que é qualidade no serviço educacional, é então que surge a necessidade de buscar respostas naqueles que os recebem, ou seja, o acadêmico.O presente estudo teve como finalidade identificar qual a percepção dos acadêmicos do curso de Ciência Contábeis da UNEMAT apontando qual o grau de satisfação dos discentes quanto a qualidade do ensino ofertado, aplicando o Modelo Hedperf sugerido por Firdaus (2006). Através das informações coletadas pelo Modelo, onde cinco dimensões são avaliadas, incluindo aspectos não acadêmicos pode-se atingir o objetivo da pesquisa que era identificar o grau de satisfação do acadêmico quanto ao curso de Ciências Contábeis oferecido pela UNEMAT. Desta forma o presente artigo estruturou-sede seguinte modo: I)Introdução ao tema proposto com breve relato quanto a preocupação das empresas com planejamento de marketing, preocupação com mercado e apresentação dos objetivos propostos pela pesquisa; II) Revisão bibliográfica com conceitos sobre imagem, percepção de qualidade ligada a características de bens ou serviços, tangibilização ou seja, associação do serviço prestado a características especificamente físicas; III) Caracterização do Modelo Hedperf, estrutura dimensões de análise, relação entre serviço qualidade e serviço performance; IV) Metodologia direcionada aos objetivos desta pesquisa utilizando-se do Modelo Hedperf, tabulações e uso de estatística simples e médias; V) Apresentação, analise e discussão dos dados coletados, com apresentação dos dados observados na pesquisa, e por fim, VI) Considerações finais a respeito do estudo e seus resultados, apontamento dos pontos fortes de fracos, sugestão de possíveis correções ou ações de melhorias a serem efetuadas.

Palavras-chave: Qualidade. Imagem. Tangibilização. Modelo Hedperf. Curso de Ciências Contábeis. Perspectiva Acadêmica.

\footnotetext{
1 Acadêmico do curso de Ciências Contábeis da UNEMAT - Campus de Tangará da Serra, e-mail: damattashow@hotmail.com.

${ }^{2}$ Mestrado em Agricultura Tropical pela Universidade Federal de Mato Grosso, e Professora Assistente da Universidade do Estado de Mato Grosso. email: karine@unemat.br

3 Mestre em Economia pela Universidade Federal de Mato Grosso (2009) no Programa Agronegócios e Desenvolvimento Regional. Graduado em Ciências Contábeis pela Universidade do Estado de Mato Grosso (2003) e pós-graduado em finanças e gestão empresarial também pela UNEMAT (2006). Atua como professor titular do departamento de Ciências Contábeis da Universidade do Estado de Mato Grosso na área de contabilidade aplicada, campus de Tangará da Serra e participa do Grupo de Pesquisa econômico e contábil de Mato Grosso (GEPEC - MT). email: cleitonfranco@unemat.br.

${ }^{4}$ Possui graduação em Administração de Empresas pela Universidade do Estado de Mato Grosso (2005) e graduação em Ciências Contábeis pela Universidade do Estado de Mato Grosso (2009). Possui título de Especialista - MBA em Gestão Empresarial de Cooperativas pela Fundação Getúlio Vargas - FGV (2010). Atualmente é gerente administrativo e contador da Cooperativa Agroindustrial Deciolândia e professor interino da Universidade do Estado de Mato Grosso. email: marcelo.evandro@unemat.br
} 


\section{INTRODUÇÃO}

Nas ultimas três décadas cresceu a preocupação das empresas quanto ao planejamento de marketing e a projeção da imagem das mesmas junto a seu público consumidor. (LAS CASAS, 2002) Não diferente das demais empresas, as instituições de ensino preocupadas em conhecer sua imagem no mercado e assegurarem que elas reflitam de forma fidedigna a verdadeira qualidade oferecida através de seus serviços passaram a dar foco e desenvolver esta área de conhecimento dentro de sua política de gestão (KOTLER; FOX, 1994).

Segundo Karsaklian (2011) a imagem é um conjunto de percepções de um consumidor sobre um determinado produto, empresa, pessoa ou até mesmo uma idéia que a ele está sendo ofertada, que associadas a estímulos e a um número variável de atributos que descriminam o "produto", cuja a percepção desses atributos pelo consumidor acontece de forma variável onde cada um absorve essas informações e projeta a imagem de forma pessoal (FOX, 1994).

Nickels (1976, p.413) fez a seguinte afirmação “A imagem é função tanto da informação como também da experiência que o cliente tem com o fornecedor."

Kotler e Fox (1994), afirmam também que uma instituição de ensino preocupada com o mercado, tem forte interesse em saber como seu público vê as instituições com seus programas educacionais e de serviços, uma vez que as pessoas utilizam ou que pretendem fazer uso dos serviços ofertados pela escola ou faculdade se relacionam freqüentemente a sua imagem, não necessariamente a realidade apresentada pela empresa.

Estas apresentam alta qualidade, públicos que possuem uma imagem negativa de uma instituição de ensino vão evitá-la ou desprestigiá-la, e aqueles que possuem uma imagem positiva ficarão indecisos.

Analisando o contexto apresentado pelos diversos autores a presente pesquisa destinase a responder a seguinte pergunta: Qual a imagem da instituição de ensino superior UNEMAT e a qualidade do ensino de graduação sob a percepção dos acadêmicos do curso de ciências contábeis campus de Tangará da Serra - MT? Para que possamos responder esta pergunta o presente estudo tem como objetivo geral identificar junto aos acadêmicos do curso de ciências contábeis do campus de Tangara da Serra qual a imagem ele possui da instituição de ensino UNEMAT e a qualidade do ensino de graduação ofertada pela mesma. Para orientação destes objetivos, são propostos os seguintes objetivos específicos: a) Diagnosticar a percepção de qualidade dos acadêmicos do Curso de Ciências Contábeis; b) Identificar quais 
Qualidade na percepção discente do curso de ciências contábeis na Unemat de Tangará da Serra

Alexandro da Matta Sanches

Karine Medeiros Anunciato

Cleiton Franco

Marcelo Evandro Alves

os pontos de maior deficiência; c) Fornecer informações acerca da instituição visando à melhoria da qualidade de ensino e conseqüentemente da imagem da mesma.

Este estudo se justifica pelo seu crivo científico e pela possibilidade de estar contribuindo para o continuo processo de aprimoramento e melhoria da qualidade de ensino nas instituições de ensino superior - IES. Neste caso com enfoque voltado ao curso de ciências contábeis, oferecendo alternativas de instrumentos de avaliação, dando à instituição a possibilidade de conhecer sua imagem perante seus acadêmicos e não tão somente a ótica de órgãos governamentais como Ministério da Educação - MEC que possuem a prerrogativa de controle e avaliação sobre as mesmas. A proposta também serve como fonte de subsídios para o avanço do conhecimento científico na área e assim agregar melhorias as IESs. Este artigo teve como base o artigo de Poffo (2012).

\section{REFERENCIAL TEÓRICO}

\subsection{Qualidade}

A qualidade está ligada as características de bens, objetos, pessoas ou serviços que distinguem umas das outras (HOLANDA, 2010), de acordo com os atributos as pessoas julgam se algo é de boa ou má qualidade.

Segundo Hoffman e Bateson (2003), a qualidade em serviços pode ser percebida de acordo com o grau de satisfação daquele que o recebe, ou seja, quanto maior a satisfação melhor foi a qualidade do serviço prestado. Os autores também afirmam que uma das maneiras de se oferecer um serviço de qualidade e envolver os clientes no processo, assim os mesmos vão conduzindo e norteando a prestação de serviço de forma que lhe agradem da melhor maneira.

Outra forma de perceber a qualidade da prestação de um serviço comumente utilizada pelas pessoas e através da tangibilização do mesmo, conforme afirma Karsaklian (2011). O autor expõe em sua obra a idéia de que as pessoas tendem a associar os serviços prestados a características físicas da empresa como aparência, layout, apresentação e tratamento oferecidos pelos funcionários.

De forma sucinta em sua obra Poffo (2012), define que qualidade de um serviço é aquilo que o cliente quer da forma na qual julga ser a ideal, e que portanto, toda e qualquer 
Qualidade na percepção discente do curso de ciências contábeis na Unemat de Tangará da Serra

Alexandro da Matta Sanches

Karine Medeiros Anunciato

Cleiton Franco

Marcelo Evandro Alves

organização deve buscar de forma constante se aperfeiçoar de forma a atender as necessidades de seu público alvo, por isso a importância de se identificar a percepção dos discentes no que tange a qualidade do ensino ofertado.

\subsection{Modelo Hedperf Adaptado}

Hedperf é uma sigla em inglês dada para Higher Education Performance ou em português desempenho do ensino superior. Desenvolvido por Firdaus (2006), consiste em um modelo de avaliação de IESs que leva em consideração cinco dimensões em qualidade observadas pelos alunos sendo elas, a)aspectos não acadêmicos; b)aspectos acadêmicos; c) reputação; d) acesso; e) conteúdos programáticos. Segundo Poffo (2012), este modelo foi desenvolvido através dos instrumentos de estudos que levam em consideração a relação serviço qualidade e serviço performance (SERVQUAL e SERVPERF).

O modelo de avaliação oferecido por Firdaus foi instrumento de pesquisa que mais se aproxima das diversas referencias bibliográficas que serviram de base para a composição desta pesquisa. Os demais modelos de avaliação levantados para realização desta pesquisa não consideram dimensões das quais não estejam ligadas diretamente a didática de ensino, ou por sua vez não possuem enfoque voltado a prestação de serviços educacionais, o que compromete a eficiência da pesquisa conseqüentemente o resultado da mesma.

Corroborando com Firdaus, Poffo (2012) faz uso do Modelo Hedperf Adaptado em sua pesquisa e o confirma-o como sendo o modelo mais confiável para se captar as percepções dos acadêmicos quanto ao que tange a qualidade de ensino ofertada pelas IESs, pois considera as diversas vertentes que levam o corpo discente a gerar uma imagem positiva ou negativa das instituições. A pesquisa de Poffo (2012) consegue demonstrar com clareza a satisfação ou insatisfação do corpo acadêmico, e os pontos geradores dessa opinião.

\subsection{Marketing de Serviços}

Segundo Las Casas (2002), na década de 80 houve um intenso desenvolvimento do estudo de mercadológico em diversos setores da economia com crescimento ainda mais acentuado no setor de serviços. A mudança na mentalidade empresarial pode ser apontada como um dos fatores que contribuíram para isso, no sentido de que, hoje em dia profissionais autônomos já 
Qualidade na percepção discente do curso de ciências contábeis na Unemat de Tangará da Serra

Alexandro da Matta Sanches

Karine Medeiros Anunciato

Cleiton Franco

Marcelo Evandro Alves

aceitam a idéia de aplicar técnicas mercadológicas em seus negócios. Através destas mudanças que ocorreram permitiu-se a utilização de recursos mais avançados na comercialização de seus serviços inclusive em áreas antes consideras anti-marketing, como entidades filantrópicas, organizações religiosas, instituições de ensino etc.

O termo "imagem" começou a ser usado popularmente na década de 50 e atualmente tem sido utilizado em diversos contextos sendo um dele a imagem institucional. Karsaklian (2011) refere-se à imagem como sendo a soma de crenças, idéias e impressões que uma pessoa tem de um objeto, no caso deste trabalho o objeto na realidade não é um bem tangível, mas sim a prestação de serviço no qual nos remete a dúvida sempre existente de como mensurar um bem não tangível. Muitos métodos têm sido propostos para mensurar imagens. Descreve-se uma abordagem de duas etapas: primeira, mensurando quão familiar e favorável é a imagem da instituição, segunda, mensurando sua localização ao longo das dimensões mais relevantes (chamado diferencial semântico).

A primeira etapa é avaliar o grau de familiaridade existente entre o individuo e a instituição avaliando qual o conhecimento existente entre ambos. Os resultados indicaram a conscientização pública da instituição e o que possuírem maior familiaridade são solicitados a descrever quão favoráveis são.

Segundo Karsaklian (2011), as instituições de ensino devem se utilizar de seu diferencial semântico, com o desenvolvimento de um conjunto de dimensões relevantes, estabelecendo escalas como de avaliação boas ou más, potencia fortes ou fracas e de atividades ativas ou passivas, procurando manter um número pequeno de dimensões evitando com isso a fadiga ao avaliar. Usando estas escalas como guia o pesquisador pode remover escalas que falhem.

“O referencial semântico é uma ferramenta de mensuração de imagem flexível que podem fornecer as seguintes informações úteis: A instituição pode descobrir como é vista por um público específico e como seus principais concorrentes são vistos por este público.” (KARSAKLIAN,2011)

A autora ainda conclui sua teoria afirmando que o ideal é a combinação de teorias tendo em vista a intangibilidade constante na prestação de serviços, em outras palavras, uma imagem é influenciada tanto pelas características objetivas do objeto, como pelas características subjetivas de quem o vê. 
Qualidade na percepção discente do curso de ciências contábeis na Unemat de Tangará da Serra

Alexandro da Matta Sanches

Karine Medeiros Anunciato

Cleiton Franco

Marcelo Evandro Alves

"O custo e a eficácia da estratégia de imagem dependem, é claro, da imagem atual e dos verdadeiros atributos do local." (LAS CASAS, 2002)

Karsaklian (2011) diz em sua obra que o primeiro passo a ser dado por um gestor educacional que deseja mudar a imagem de sua instituição é identificar qual a sua imagem atual, seus pontos fortes e principalmente seus pontos fracos. O segundo passo é a definição de quais problemas ele deseja priorizar, qual a contribuição para favorecer a imagem global, tipo de estratégia de mudança, custo, tempo. "As instituições estão interessadas em mensuração e modificação da imagem porque assumem que existe um relacionamento direto entre a imagem publica da instituição e o comportamento decorrente das pessoas. (KARSAKLIAN, 2011)

\subsection{Tangibilização de Serviços}

Para Hoffman e Bateson (2003) por causa da intangibilidade dos serviços, é difícil para os clientes avaliarem objetivamente a sua qualidade, por isso muitas vezes eles utilizamse das evidencias físicas que cercam o serviço como, exterior e interior do estabelecimento layout, equipamentos, temperatura, aparência e tratamento dos funcionários, formulários, higiene entre outros. Essas evidências físicas colaboram na socialização entre acadêmico e instituição de ensino fazendo com que os mesmos projetem uma imagem favorável e positiva associadas à verdadeira qualidade.

Estrategicamente, o pessoal de serviço é uma importante fonte de diferenciação de produto. Muitas vezes um desafio para uma organização de serviço é distinguir-se de outras organizações semelhantes no pacote de benefícios que oferece ou no seu sistema de prestação de serviços. O pessoal constitui a essência do produto da maioria das empresas de serviço.

Hoffam e Bateson (2003), afirmam que o ideal para satisfazer um cliente é envolve-lo no processo como co-produtor de modo atender da melhor forma suas necessidades pois ele melhor que ninguém as conhece. A satisfação do cliente é uma das áreas mais estudadas em marketing sendo esta uma das áreas de maior crescimento em termos de pesquisa de mercado." Na verdade, satisfazer é exceder as expectativas dos clientes podem resultar em vários benefícios valiosos para a empresa. A propaganda positiva boca a boca feitas por clientes muitas vezes se traduz em novos clientes.A satisfação atualiza nos clientes suas percepções da qualidade do serviço.” (HOFFMAN; BATESON, 2003) 


\section{METODOLOGIA}

Para atingir os objetivos propostos neste trabalho a tipologia quanto a abordagem do problema é a quantitativa, tendo em vista que visa identificar qual a percepção dos acadêmicos do curso de ciências contábeis sobre a qualidade dos serviços prestados pela UNEMAT. Pires (2010) afirma que o ser humano sente a necessidade da busca por novos conhecimentos e é neste momento que surgem as estratégias de pesquisa que variam de acordo com o problema a ser estudado. De acordo com a necessidade de cada pesquisa uma determinada metodologia deve ser aplicada de modo a imprimir maior eficiência na busca por respostas.

Diante das forças ambientais que conduzem as organizações a mudarem seus objetivos, metas e processos, as instituições de ensino, hoje mais do que nunca,se vêem induzidas a acompanharem essas mudanças sob a forma de melhorias nos serviços prestados a seus alunos, e, conseqüentemente, as comunidades nas quais se inserem. (NEVES, 2010). Por isso surge à necessidade de criar métodos de avaliação de desempenho que englobam o maior numero de itens e perspectivas diferentes. Para este estudo especificamente optou-se por um modelo estruturado em perguntas fechadas direcionadas ao corpo discente do curso de Ciências Contábeis da UNEMAT - o Modelo Hedperf Adaptado. O modelo adotado justificase por se tratar de ser um instrumento com características mais apropriadas para a investigação e constatação da questão problema e objetivos propostos segundo (DEPINE,2012).

Com enfoque mais voltado especificamente para área de marketing Samara e Barros (2007) alegam que os estudiosos do marketing utilizam de diferentes nomes, mas que porém elas não se diferem em seu conteúdo, mas sim na fonte de dados a ser utilizada e a amplitude do estudo conforme os objetivos e tipos de analise que pretendem fazer - quantitativa ou qualitativa - de acordo com o controle das variáveis em estudo.

Os "deskresearch" ou estudos exploratórios, tem como principal característica a informalidade, a flexibilidade e a criatividade, e neles procura-se obter um primeiro contato com a situação a ser pesquisada ou a um melhor conhecimento do objeto em estudo ou das hipóteses a serem confirmadas. 
Qualidade na percepção discente do curso de ciências contábeis na Unemat de Tangará da Serra

Alexandro da Matta Sanches

Karine Medeiros Anunciato

Cleiton Franco

Marcelo Evandro Alves

Foi utilizado como campo exploratório o quadro de acadêmicos do curso de Ciências Contábeis do Campus de Tangara da Serra localizado as margens da Rodovia MT 358 KM 7 Jardim Aeroporto município de Tangara da Serra - MT, no período de setembro de 2013 aplicando o Modelo Hedperf Adaptado. O universo total de discentes compreende um total de 364 acadêmicos que dentre estes 150 participaram da pesquisa sendo 75 ingressantes do primeiro ao quarto semestres, e 75 concluintes do quinto ao oitavo semestres. As informações coletadas através dos questionários foram devidamente tabuladas, posteriormente analisados pelo pesquisador considerando acadêmicos nos semestres iniciais e finais do curso. Essa divisão justifica-se pela necessidade de apontamento de pontos em comum e discrepantes dos discentes referentes a qualidade e seu grau de experiência e conhecimento a respeito do curso. Conforme a Tabela 1 que representa o universo total e a divisão do mesmo para analise:

Tabela 1: Corpo discente do curso de Ciências Contábeis UNEMAT

\begin{tabular}{|c|c|c|c|c|}
\hline Curso & $\begin{array}{c}\text { Total de } \\
\text { discentes }\end{array}$ & $\begin{array}{c}\text { Discentes } \\
\text { iniciantes }\end{array}$ & $\begin{array}{c}\text { Discentes } \\
\text { concluintes }\end{array}$ & $\begin{array}{c}\text { Total de discentes } \\
\text { investigados }\end{array}$ \\
\hline Ciências Contábeis & $\mathbf{3 6 4}$ & $\mathbf{7 5}$ & $\mathbf{7 5}$ & $\mathbf{1 5 0}$ \\
\hline
\end{tabular}

Elaboração: Autor.

A tabela 1 permiti estabelecer uma comparação entre o universo real e a amostra utilizada na pesquisa e verificar como foi distribuída. Utilizando o Modelo Hedperf Adaptado a pesquisa fez uso de 5 dimensões de qualidade, subdivididas em 48 itens o que permitiu ao entrevistado optar por respostas em escala de 1 a 5, sendo que, 1 péssimo, 2 ruim, 3 regular, 4 bom e 5 ótimo. Esta escala recebe o nome de escala Likert e proporciona avaliar as perspectivas multifatoriais que determinam a concepção de qualidade do aluno.

Os resultados foram apresentados seguindo a sequiência do formulário de entrevista do Modelo Adaptado Hedperf, demonstrando de forma generalizada sem considerar as variantes, acadêmicos ingressantes versos concluintes. Foram realizados 150 questionários onde 4 dos mesmos foram desconsiderados da contagem devido a algum tipo de rasura, o que poderia comprometer a integridade da pesquisa e sendo aproveitado um universo de 146 questionários.

Ao analisar os dados coletados notou-se que em sua totalidade a opção "regular" foi opção mais escolhida pelos acadêmicos em todos os itens avaliados. Segundo o dicionário Aurélio define a palavra regular como sendo aquilo que é mediano, ou seja, aquilo que não é nem bom nem ruim. 
Qualidade na percepção discente do curso de ciências contábeis na Unemat de Tangará da Serra

Alexandro da Matta Sanches

Karine Medeiros Anunciato

Cleiton Franco

Marcelo Evandro Alves

Considerando que em sua grande maioria os acadêmicos classificaram os itens como

sendo regulares, verificou-se a necessidade de se apurar de maneira mais clara qual a tendência o item avaliado possuía, se positiva ou negativa. Utilizou-se então a seguinte metodologia: Classificou-se as opções bom e ótimo como sendo tendências positivas sobre os itens analisados, e, as opções ruim e péssimo como sendo tendências negativas sobre cada item. Desconsiderou-se as respostas regulares para que ficasse mais clara a tendência positiva ou negativa. O procedimento estatístico utilizado foi o de somatória e média simples.

Através destes procedimentos metodológicos permitiu-se o levantamento de dados numéricos que ajudam a tangibilizar a imagem projetada pelos acadêmicos da IES analisada.

\section{RESULTADOS}

Neste contexto, seguindo a metodologia proposta inicialmente a primeira dimensão a ser demonstrada através do Modelo Hedperf está ligada a aspectos acadêmicos onde foram observados 10 itens.

A Tabela 2 apresenta a correlação entre satisfação geral e a dimensão de aspectos acadêmicos sobre o curso de ciências contábeis da UNEMAT: 
Qualidade na percepção discente do curso de ciências contábeis na Unemat de Tangará da Serra

Alexandro da Matta Sanches

Karine Medeiros Anunciato

Cleiton Franco

Marcelo Evandro Alves

Tabela 2 Correacãa entrie Satisfação Geral com os Atributos da Dimensão Q Qualidadede: Aspectos Acadêmicos

Grupo 1: Relacão entre Satisfacão Geral com os Atributosos da Dimensão da Oualidade: Aspectos Acadêmicos em percentuais \%

Positiva (P) Negativa (N) P $\Leftrightarrow N$

Otimo Bom Reggular Ruim Pessimo

1 Didática do professor a o responder a s minhas perguntas sobre o conteíido.

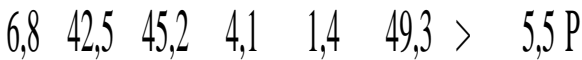

2 Cortesia do professor.

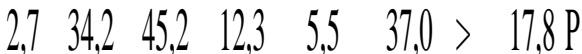

3 Disponbilididade mostrada pelo professor guando o aluno precisa de auxilito.

$9,631,5 \quad 46,6 \quad 9,6 \quad 2,7 \quad 41,1>12,3 \mathrm{P}$

4 Sinceridade do professor parar eresolver mens spoblemas suanclos solicitados.

$6,846,641,1 \quad 9,6 \quad 2,7 \quad 53,4>12,3 \mathrm{P}$

5 Entusiasmo do professor para me ensinar.

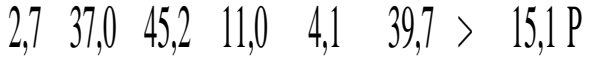

6 Interexção do professor dentro da sala de aulla.

$9,6 \quad 39,7 \quad 38,4 \quad 11,0 \quad 1,4 \quad 49,3>12,3 \mathrm{P}$

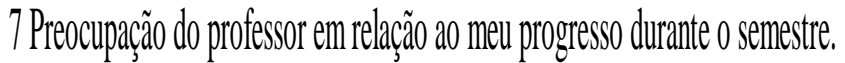

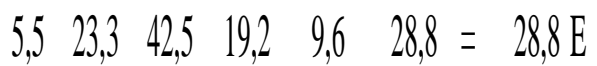

8 Disponibilitidade do tempo do professor para consulta.

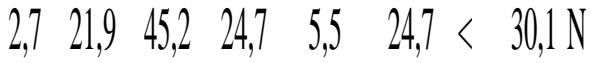

9 Comhecimentro einstruçãa dos professsores em relaçãa as discipininas.

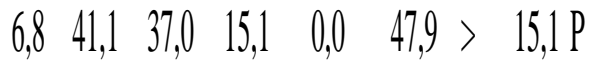

10 Nivele geral de satisfacão com o corpo docente e instituicãa de ensino

$6,8 \quad 37,0 \quad 45,2 \quad 5,5 \quad 5,5 \quad 43,8>11,0 \mathrm{P}$

Elaboração: Autor com base nos dados da pesquisa.

Como demonstrado acima, em sua totalidade os 10 itens apresentaram como maior indicador a opção regular, porém alguns pontos chamam atenção, como o item 4, que apresentou o melhor índice de aprovação, sendo em sua maioria bem avaliada pelos acadêmicos, na contra mão dos demais, o item 8 - Disponibilidade de tempo do professor para consulta foi o único que apresentou tendência negativa apresentando a pior avaliação dentre os demais. Este resultado pode se dar devido ao fato de que grande parte dos professores em atividade não serem titulares de suas cadeiras, o que não os obriga a ter dedicação exclusiva a universidade, ou até mesmo pelo número excessivo de acadêmicos matriculados no curso. Curiosamente o item 7 foi o que apresentou a maior regularidade entre as respostas, tendo os mesmos percentuais positivos e negativos, o que confirma a sua plena regularidade, fato que pode servir de alerta, pois não se sabe a satisfação sobre o item tende a aumentar ou diminuir pois não possui-se informações anteriores a respeito . No geral esta dimensão apresentou-se com um bom nível de satisfação dos acadêmicos, pois em sua maioria foi classificada como regular com tendência positiva. 
Qualidade na percepção discente do curso de ciências contábeis na Unemat de Tangará da Serra

Alexandro da Matta Sanches

Karine Medeiros Anunciato

Cleiton Franco

Marcelo Evandro Alves

Seguindo a seqüência das análises, a próxima dimensão está relacionada a aspectos da reputação que engloba os itens de 11 a 21 do questionário Modelo Hedperf Adaptado.

Ao observar os resultados apurados sobre a dimensão reputação, notou-se que a mesma não apresentou uma imagem tão positiva quanto a dimensão anteriormente analisada. Como mostram a tabela 3 através de percentuais, as escolhas dos acadêmicos sobre cada item avaliado:

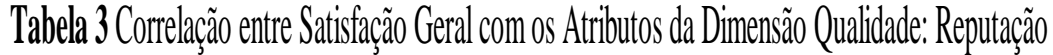

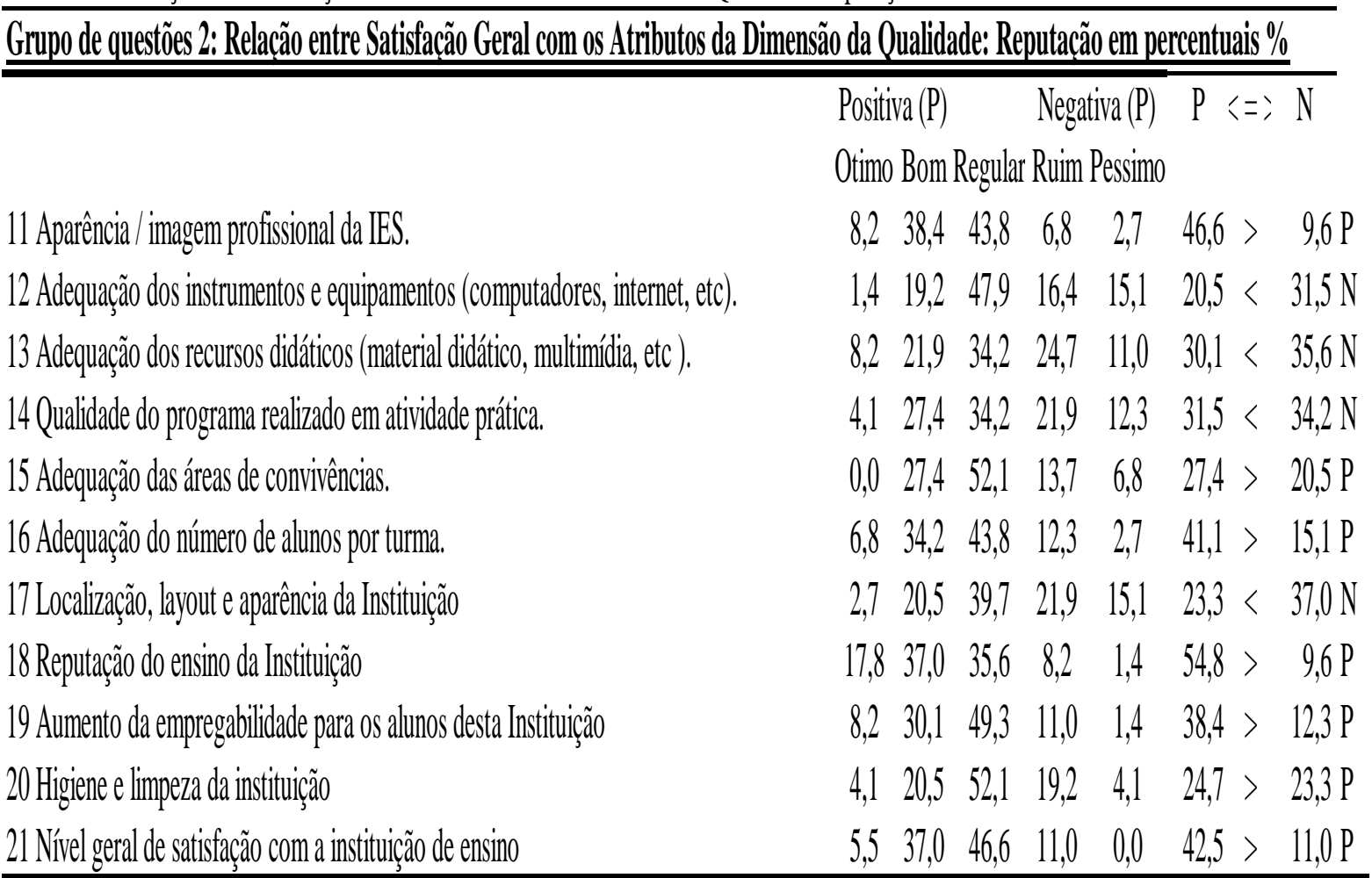

Elaboraçãa: Autor com base nos dados da pesquisa.

Esta dimensão possui 10 itens de avaliação dos quais 4 apresentaram avaliação entre regular e péssima. Estes totais de itens negados correspondem a quase $40 \%$ da dimensão analisadas. Os itens 12,13,14 apresentaram avaliação com tendência negativa. Estes itens englobam a parte de estrutura física do curso como, laboratório de informática com máquinas defasadas, sistema operacional de difícil operação, escassez ou falta de equipamentos como televisores, retroprojetores, aparelhos de DVD e de som, podem ser os causadores desta "má impressão"sobre os itens avaliados. O item 17 que se trata da localização, layout e aparência da instituição foi o que apresentou maior percentual de rejeição. Atualmente o campus está localizado a $7 \mathrm{~km}$ do centro da cidade, e o trecho se encontra em obras de duplicação, as salas Volume 3, Número 5 Revista UNEMAT de Contabilidade Jan./Jun. 2014

UNEMAT 
Qualidade na percepção discente do curso de ciências contábeis na Unemat de Tangará da Serra

Alexandro da Matta Sanches

Karine Medeiros Anunciato

Cleiton Franco

Marcelo Evandro Alves

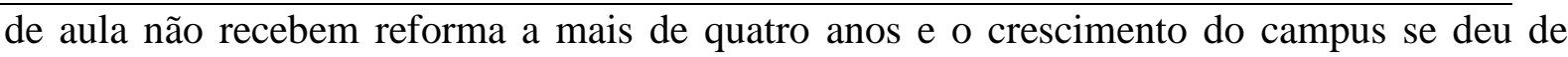
forma desordenada sem qualquer tipo de padrão ou planejamento, tudo isso pode ter contribuído para a má avaliação do item.

Entre os aspectos positivos destaca-se o item 18, o mais especifico, que pergunta direto ao acadêmico qual a reputação da IES segundo a sua ótica.

Em seguida verificou-se os resultados da terceira dimensão analisada, a de conteúdo programático:

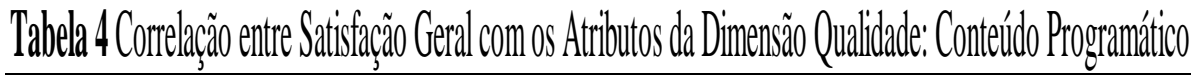

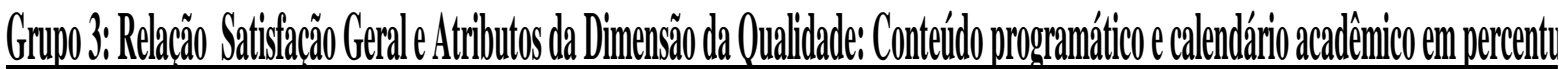

Positiva (P) Negativa (P) $P \Leftrightarrow N$

Otimo Bom Reçuar Ruim Pessimo

22Equillbrio do nivel de dificuldade entre os livros adotados pelos professores.

$1,4 \quad 30,1 \quad 34,8 \quad 9,6 \quad 4,1 \quad 31,5>13,79$

23 Horário das allas oferecidas pela Instituciçã

$5,5 \quad 26,0 \quad 37,0 \quad 15,1 \quad 16,4 \quad 31,5=31,5 \mathrm{E}$

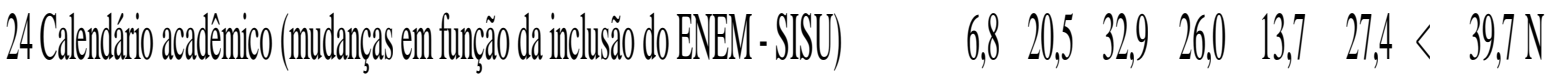

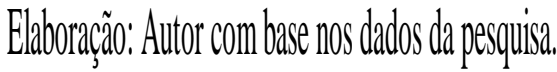

$\mathrm{Na}$ terceira dimensão abordada, a de conteúdo programático, apresentou três resultados diferentes em cada um dos seus três itens. No item 22, como os demais, teve a maioria das respostas dadas, classificando o item como regular, mas com tendências positivas ao item proposto. O item 23 por sua vez, apresentou um estremo equilíbrio entre as respostas, afirmando-o como tendo uma imagem regular perante os acadêmicos. Por fim no terceiro e ultimo item da dimensão, o item de numero 24 apresentou uma veemente negativa chegando até mesmo a superar o percentual de respostas regulares.

Seguindo a seqüência proposta pelo Modelo Hedperf Adaptado,analisou-se a quarta dimensão que tem ligação com os aspectos não acadêmicos, conforme Tabela 5: 
Qualidade na percepção discente do curso de ciências contábeis na Unemat de Tangará da Serra

Alexandro da Matta Sanches

Karine Medeiros Anunciato

Cleiton Franco

Marcelo Evandro Alves

Tabela 5 Correlação entre Satisfação Geral com os Atributos da Dimensão Qualidade: Aspéctos não Acadêmicos

Grupo t: Relacão entre Satisfacãa Geral com os Atributos da Dimensão da Qualidade: Aspectos não acadêmicos em percentuais \%

Positiva (P) Negativa (P) $P \Leftrightarrow N$

Otimo Bom Regular Ruim Pessimo

25 Interesse do pessoal adminisistativo em resolver meus problemas.

$\begin{array}{llllllll}9,6 & 21,9 & 43,8 & 12,3 & 12,3 & 31,5 & > & 24,7 \mathrm{P}\end{array}$

26 Atenção individual e cuidadosa dada pelo pessoal administrativo.

$\begin{array}{lllllll}5,5 & 19,2 & 47,9 & 16,4 & 11,0 & 24,7 & <\end{array} 27,4 \mathrm{~N}$

27 Tratamento das consultas e reclamações do pessoal administrtativo.

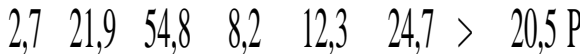

28 Disponibilitidade do pessoal administrativo para atender a meus pedidos.

$4,1 \quad 23,3 \quad 42,5 \quad 24,7 \quad 5,5 \quad 27,4<\quad 30,1 \mathrm{~N}$

29 Forma como a administraçãa mantém o regisisto dos alunos.

$13,7 \quad 24,7 \quad 42,5 \quad 15,1 \quad 4,1 \quad 38,4>19,2 \mathrm{P}$

30 Pontualidade na entrega dos serviçcos solicitados.

310 horário de funcionamento dos serviços administrativivos.

$\begin{array}{lllllll}8,2 & 31,5 & 37,0 & 17,8 & 5,5 & 39,7 & >\end{array} 23,3 \mathrm{P}$

32 Cordialidade do pessoal administrativo em relação aos alunos.

$\begin{array}{llllllll}9,6 & 37,0 & 34,2 & 11,0 & 8,2 & 46,6 & > & 19,2 \mathrm{P}\end{array}$

$\begin{array}{llllllll}8,2 & 26,0 & 47,9 & 8,2 & 9,6 & 34,2 & > & 17,8 \mathrm{P}\end{array}$

33 Comunicação do pessoal administrativio comos alunos.

$\begin{array}{llllll}6,8 & 21,9 & 41,1 & 19,2 & 11,0 & 28,8\end{array}<30,1 \mathrm{~N}$

34 Comhecimento do pessoal administrativo em relaçãa aos sistemas e procedimentos.

\begin{tabular}{llllllll}
6,8 & 35,6 & 34,2 & 17,8 & 5,5 & 42,5 & $>$ & 23,3 \\
\hline
\end{tabular}

35 Segurrança confianç passada pela Instituição.

$8,2 \quad 27,4 \quad 42,5 \quad 12,3 \quad 9,6 \quad 35,6>21,9 P$

36 Atendimento do serviço de fotocópias (xerox)

$\begin{array}{lllllll}11,0 & 34,2 & 30,1 & 12,3 & 12,3 & 45,2 & >\quad 24,7 \mathrm{P}\end{array}$

37 Atendimento da biblioteca

$\begin{array}{llllllll}19,2 & 26,0 & 34,2 & 15,1 & 5,5 & 45,2 & > & 20,5\end{array}$

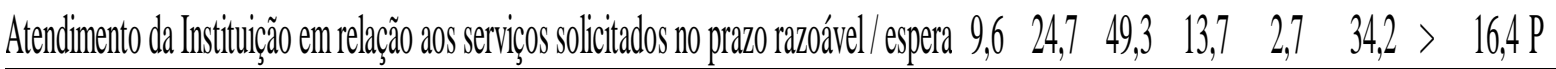
Elaboraçãa: Autor com base nos dados da pesquisa.

Esta dimensão possui 14 itens, sendo do 25 ao 38, dando enfoque maior a parte administrativa do curso. Como demonstra o quadro acima, nota-se que 11 dos 14 itens possuem uma avaliação positiva sendo $25,27,29,30,31,32,34,35,36,37$ e 38, com destaque para o item 31 que possui o maior percentual positivos dentre os demais.

Já os itens 26, 28 e 33 não apresentaram uma boa avaliação perante o corpo discente. Curiosamente são itens ligados diretamente a forma de tratamento despendido aos acadêmicos, demonstrando que os mesmos não estão satisfeitos com o tratamento que estão recebendo dos funcionários da instituição. Políticas de recursos humanos como, treinamentos, ações motivacionais, desenvolvimento de plano de cargos e salários podem contribuir para a melhoria destes itens que foram mal avaliados. Conforme Hoffman e Bateson (2003), estas evidencias como apresentação, forma de tratamento dos funcionários fazem com que o 
Qualidade na percepção discente do curso de ciências contábeis na Unemat de Tangará da Serra

Alexandro da Matta Sanches

Karine Medeiros Anunciato

Cleiton Franco

Marcelo Evandro Alves

acadêmico se identifique com a instituição. Algo que como demonstram os resultados não vem acontecendo no momento.

Para finalizar, a quinta e última dimensão analisada, que se trata da acessibilidade dos acadêmicos a IES, a qual os resultados estão demonstrados Tabela 6:

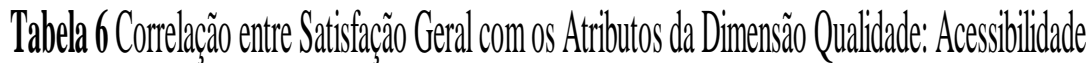

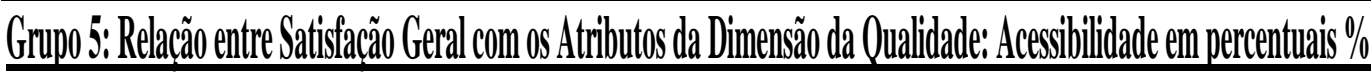

Positiva $(P) \quad$ Negativa $(P) \quad P \Leftrightarrow N$
Oimo Bom Regular Rum Pessimo

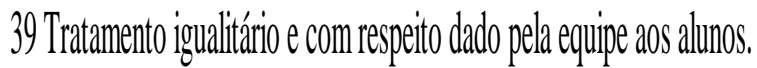

$\begin{array}{llllll}11,0 & 34,2 & 37,0 & 12,3 & 5,5 & 45,2\end{array} \quad 17,8 \mathrm{P}$

40 Liberdade dada aos alunos para utilizara as sepenenências da Instituição.

$8,2 \quad 32,941,1 \quad 12,3 \quad 5,5 \quad 41,1>17,8 \mathrm{P}$

41 Confidencialidade com que a equipe trata as informmacoes expostas pelos alunos.

$5,5 \quad 30,1 \quad 45,2 \quad 15,1 \quad 4,1 \quad 35,6>19,2 \mathrm{P}$

42 Facilidade em contatara o pessoal administrativivo pelo telefone.

$4,1 \quad 23,3 \quad 43,8 \quad 17,8 \quad 11,0 \quad 27,4<28,8 \mathrm{~N}$

430 serviço de acompanhamentio pedagógico readizado pela Institurição

$2,7 \quad 19,2 \quad 37,0 \quad 35,6 \quad 5,5 \quad 21,9<\quad 41,1 \mathrm{~N}$

40 inentivo eimteraçãa entreo a aluno promorido pela Instituçãa

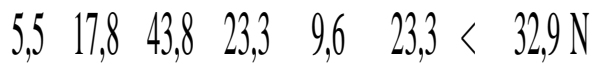

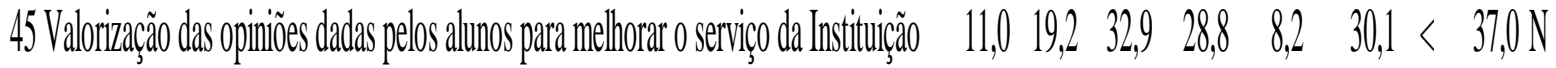

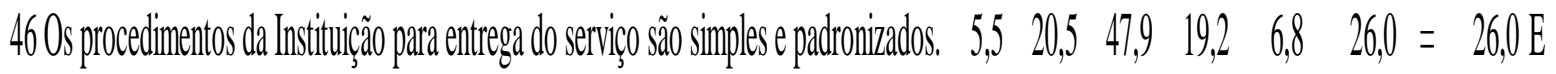

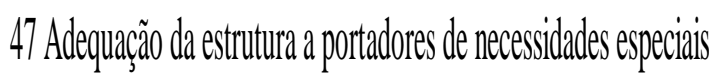

$4,1 \quad 17,8 \quad 30,1 \quad 23,3 \quad 24,7 \quad 21,9<47,9 \mathrm{~N}$

48 Estruturar de estacionamento

$9,621,923,3 \quad 12,3 \quad 32,9 \quad 31,5<45,2 \mathrm{~N}$

Elaboração: Autor com base nos dados da pesquisa

Das cinco dimensões avaliadas esta sem duvida foi a que apresentou a pior imagem perante aos acadêmicos do curso de ciências contábeis da UNEMAT. Dos 10 itens avaliados, somente 3 tiveram avaliação positiva, 39,40 e 41, e 1 item, o de número 46, que confirmou sua regularidade perante a opinião dos discentes.

Os itens 42, 43, 44, 45, 47 e 48 tiveram altos percentuais de avaliação negativa, como destaque negativo o item 47 que chama atenção pelo despreparo da estrutura da IES para atender as necessidades dos portadores de deficiência. Uma vez que não apresenta em sua estrutura física corredores com rampas de acesso, estacionamentos reservados, ou até mesmo banheiros adequados aos cadeirantes, sinalização em alto relevo que facilitem o deslocamento de deficientes visuais. Além disso, funcionários e quadro docente não possuem qualquer tipo de treinamento e recursos pedagógicos voltados ao atendimento aos portadores de Volume 3, Número 5 Revista UNEMAT de Contabilidade Jan./Jun. 2014

UNEMAT 
Qualidade na percepção discente do curso de ciências contábeis na Unemat de Tangará da Serra

Alexandro da Matta Sanches

Karine Medeiros Anunciato

Cleiton Franco

Marcelo Evandro Alves

necessidades especiais. No tocante ao estacionamento, apresenta uma estrutura precária, estando mal iluminado, sem cobertura, sem pavimentação asfáltica, nem calçamento para pedestres, além de mal sinalizado, o que contribui para que o mesmo fosse um dos itens com pior avaliação na pesquisa.

Esse despreparo da IES causa desconforto aos acadêmicos, assim como demonstrado na pesquisa, principalmente por se tratar de uma organização que tem como papel de inclusão social, promover a igualdade entre as diversidades socioculturais e a produção futuros formadores de opinião de suas comunidades.

Dentre os itens avaliados, o que mais chama atenção talvez não pelo percentual, mas pelo simples fato de ser avaliado negativamente, é o item de número 45, que trata da valorização das opiniões dadas pelos alunos para a melhoria dos serviços da instituição. Apesar de a mesma contar com um diretório acadêmico, grande parte dos acadêmicos se demonstraram descontentes com atual modelo de representação, ou sem voz ativa no que tange as decisões que envolvem a UNEMAT, o que desperta grande apreensão pois historicamente as universidades sempre foram tidas como centros de discuções, debates de idéias e berço da democracia.

Dando seqüência a análise dos dados, assim como proposto na metodologia, estabeleceu-se um comparativo entre acadêmicos iniciantes que ingressam no curso com perspectivas externas sem conhecimento da estrutura oferecida pela IES e acadêmicos concluintes que já passaram por todos os processos dentro da instituição e, portanto possuem um maior grau de informação e conhecimento sobre a mesma, podendo com isso formular uma opinião mais consistência embasada nas experiências já vivenciadas dentro da instituição.

Para que se possa identificar a mudança de percepção entre as classes de acadêmicos expressou-se o resulta em forma grafia como demonstra a figura abaixo: 
Qualidade na percepção discente do curso de ciências contábeis na Unemat de Tangará da Serra

Alexandro da Matta Sanches

Karine Medeiros Anunciato

Cleiton Franco

Marcelo Evandro Alves

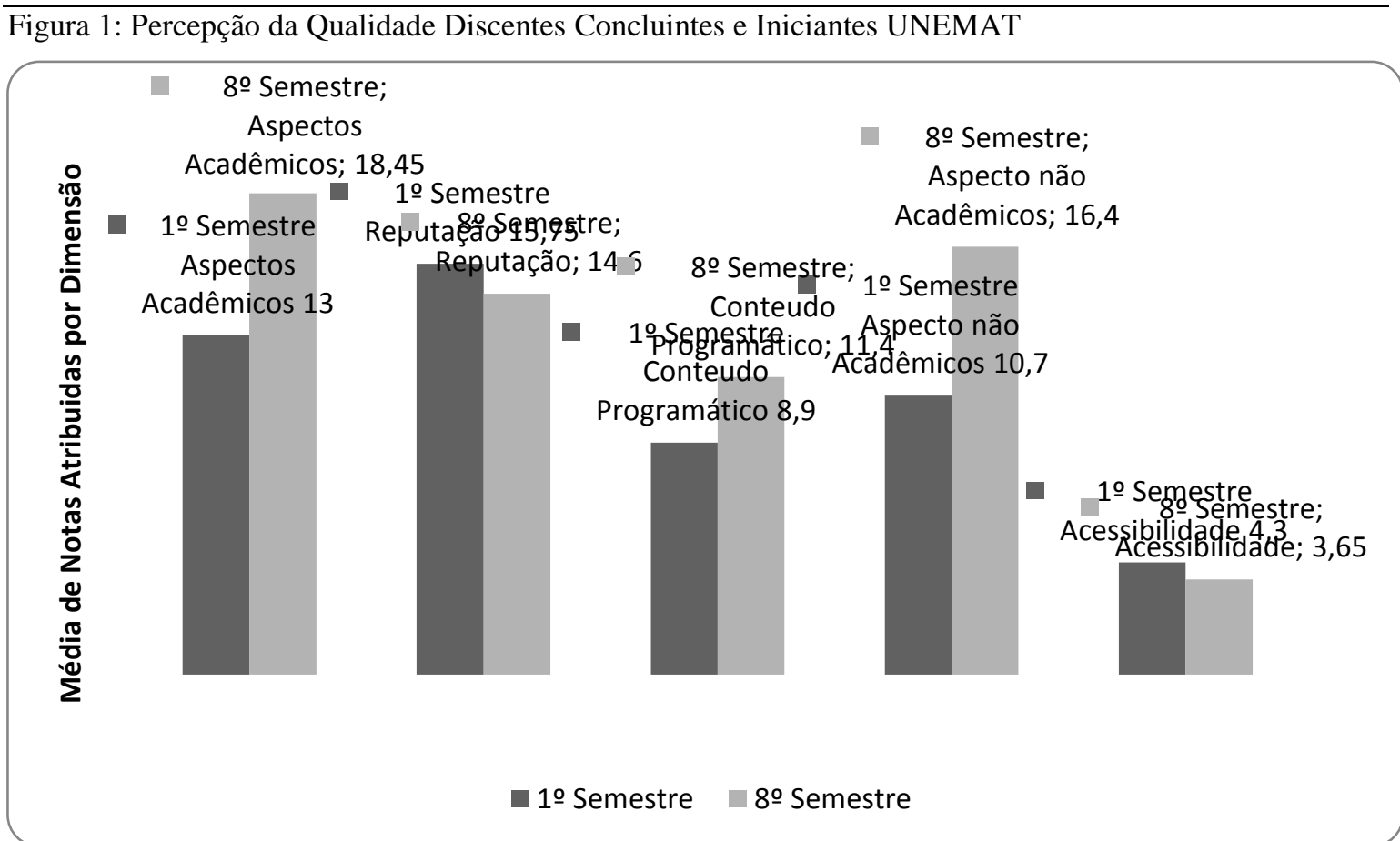

Fonte:Elaborado pelo autor com base nos resultados da pesquisa.

Nota-se na Figura 1 que a percepção de qualidade dos acadêmicos concluintes só não é mais positiva que a dos iniciantes em duas dimensões, que seriam reputação e acessibilidade e, se retornar as tabelas, nota-se que os itens mais mal avaliados constata-se que possuem certa ligação, pois são itens da parte física da instituição.

A parte positiva é que nas outras três dimensões os acadêmicos concluintes avaliaram positivamente e com uma diferença considerável dos iniciantes. Isso demonstra que a instituição apesar de possuir problemas, não chega a prejudicar a si própria. À medida que os acadêmicos vão tendo contato com os serviços prestados pela mesma, a percepção que eles agregam é a de um serviço de qualidade prestado pela mesma.

Para se ter uma impressão mais clara a respeito dos resultados desta pesquisa, demonstra-se graficamente abaixo os resultados obtidos por Poffo (2012) em sua pesquisa: 
Qualidade na percepção discente do curso de ciências contábeis na Unemat de Tangará da Serra

Alexandro da Matta Sanches

Karine Medeiros Anunciato

Cleiton Franco

Marcelo Evandro Alves

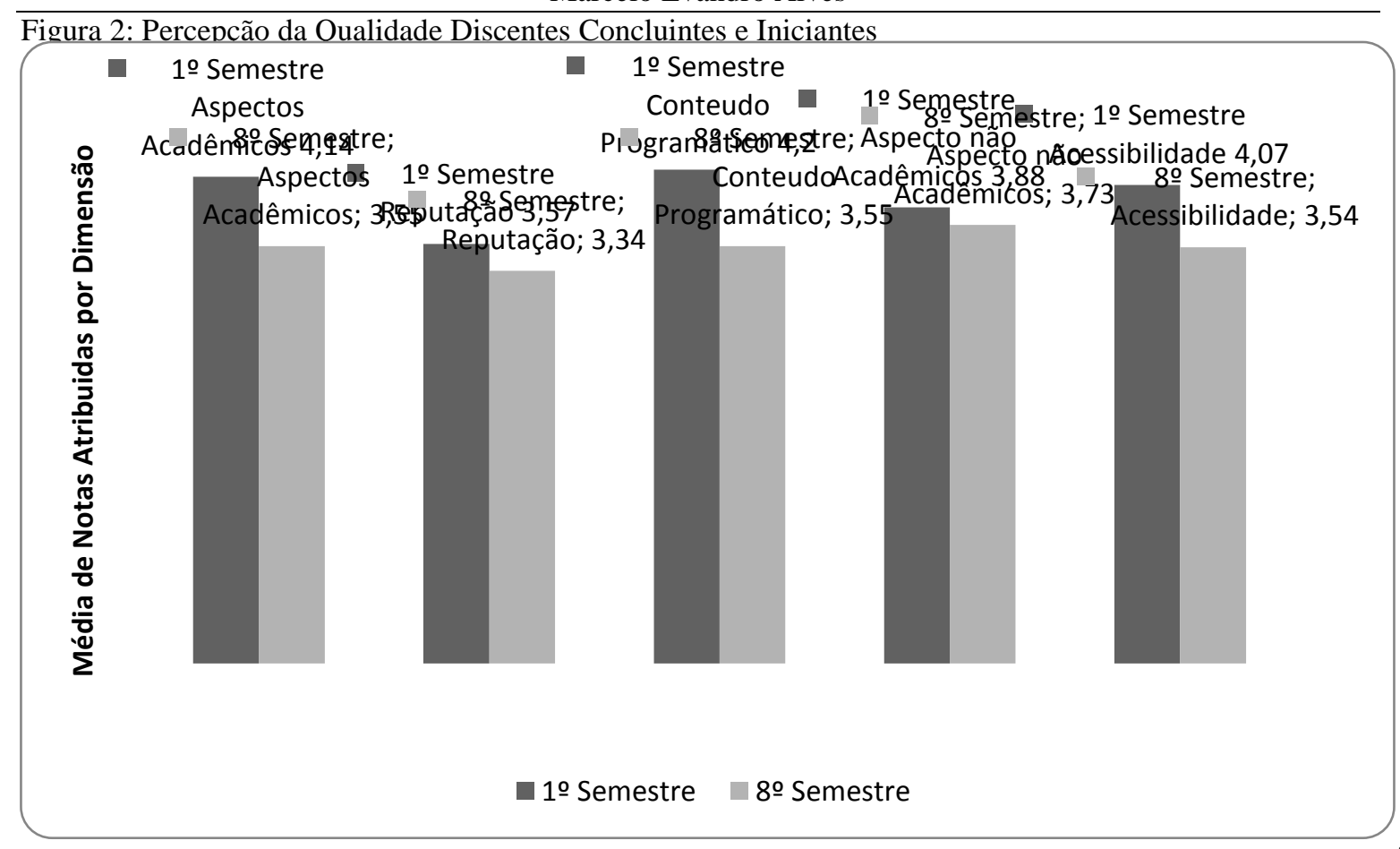

Fonte: Poffo (2012)

Ao observar os gráficos, nota-se que os resultados obtidos nesta pesquisa são diferentes aos da pesquisa de Poffo (2012), ou seja, a UNEMAT possui uma imagem mais positiva perante seus acadêmicos do que a universidade pesquisada por Poffo (2012). Varia também as dimensões com maior e menor percepção de qualidade, no caso do estudo de Poffo a dimensão com pior desempenho foi a de reputação, enquanto que nesta pesquisa a dimensão acessibilidade foi a mais mal avaliada.

Um dado interessante que os gráficos revelam é o viés com que cada uma das IES tende. No caso da instituição estudada por Poffo, os acadêmicos ingressantes possuem uma expectativa com relação a qualidade do ensino alta, a medida que os acadêmicos concluintes apresentam um grau de satisfação menor do que a dos iniciantes. No atual estudo ocorre de maneira contrária, os acadêmicos com maior experiência e conhecimento na faculdade possuem um grau de satisfação maior que o dos iniciantes. Isso demonstra que mesmo com todos os problemas apontados, a UNEMAT ainda consegue surpreender de maneira positiva seu quadro discente. 
Qualidade na percepção discente do curso de ciências contábeis na Unemat de Tangará da Serra

Alexandro da Matta Sanches

Karine Medeiros Anunciato

Cleiton Franco

Marcelo Evandro Alves

\section{CONSIDERACÕES FINAIS}

A imagem de uma instituição está intimamente ligada a qualidade de seus produtos ou serviços prestados. Se tratando de ensino superior a imagem está atrelada a qualidade do ensino ofertado pela instituição, porém, identificar e mensurar o que faz parte da qualidade de ensino se tornou o grande desafio dos gestores das IESs. Esta preocupação é tamanha que, até mesmo o governo através de seus ministérios (MEC) utilizam-se de métodos de avaliação para mensurar a qualidade do ensino. Contudo, se faz necessário observar a qualidade de ensino por varias óticas, sendo uma delas e talvez a principal, a do acadêmico.

Ao analisar as diversas informações coletadas através do questionário Hedperf Adaptado em conjunto com a bibliografia estudada, conclui-se que o curso de Ciências Contábeis da UNEMAT possui uma imagem regular com tendências positivas perante aos acadêmicos do curso de Ciências Contábeis do campus de Tangara da Serra. Porém, a instituição deveria adotar um sistema de avaliação permanente que sirva como um canal de feedback, ferramenta esta muito importante para o desenvolvimento do plano estratégico a respeito da qualidade de seus serviços prestados.

O conteúdo programático juntamente com acessibilidade, foram às dimensões que apresentaram os níveis mais baixos de satisfação perante aos alunos, devido a alguns problemas pontuais como a acessibilidade, estacionamento, horário das aulas e calendários acadêmico, por isso, assim como ficou demonstrado no resultado da pesquisa deve-se ouvir mais a opinião dos acadêmicos, envolvendo, fazendo com que ele faça parte do processo, assim como afirmam algumas teorias quanto a qualidade de serviços, envolvendo aquele que o recebe em seu processo de concessão.

A pesquisa atinge plenamente os objetivos estabelecidos, demonstrando de forma clara e contundente quais os pontos a serem melhorados pela IES, se mostrando um mecanismo eficiente na tomada de decisão para a resolução de problemas apontados. Sabe-se que, algumas das soluções esbarram em dificuldades orçamentárias, por necessitarem de recursos financeiros oriundos do estado, porém, os gestores devem estar munidos de informações que sirvam de argumentos na negociação do orçamento da instituição, apresentando as demandas da mesma e priorizando os pontos a serem melhorados.

Enfim, devem estar cientes de que a qualidade esta ligada a satisfação do cliente/aluno e que não basta apenas atender suas necessidades, mas sempre tentar surpreende-lo 
Qualidade na percepção discente do curso de ciências contábeis na Unemat de Tangará da Serra

Alexandro da Matta Sanches

Karine Medeiros Anunciato

Cleiton Franco

Marcelo Evandro Alves

positivamente, deste modo "a qualidade deixa de ser tão somente um adjetivo e passa a ser um substantivo de ação" (POFFO, 2012).

\section{REFERÊNCIAS}

FIRDAUS, Abdullah.Desenvolvimento deHEdPERF: Um NovoInstrumento de Mediçãoda Qualidade do ServiçoPara o Setor deEnsino Superior.JornalInternacional de Estudosdo Consumidor,v30, n. 6, p569-581, novembro de 2006.

HOFFMAN, K. Douglas; BATESON, John E. G.. Princípios de Marketing de Serviços: conceitos estratégias e casos. 3.ed. São Paulo: Pioneira Thomson Learning, 2003

HOLANDA, Aurélio Buarque de. Dicionário Aurélio da Língua Portuguesa.5. Ed .Curitiba: Positivo, 2010.

KARSAKLIAN, Eliane. Comportamento do Consumidor.2.Ed. São Paulo: Atlas, p.62, 2011

KOTLER, Philipe ; FOX,Karen F A. marketing Estratégico para Instituições Educacionais São Paulo atlas 1994

KOTLER, Philip; HAIDER, Donald H; REIN, Irving. Marketing Public: como atrair investiimentos, empresas e turismo para cidades, regiões, estados e países. São Paulo: Makron Books, 1994.

LAS CASAS, Alexandre L. Plano de marketing para micro e pequena empresa. São Paulo: Atlas, 2002

NEVES, Jose L. Pesquisa Qualitativa: caractésticas, usos e possibilidades. Caderno de Pesquisas em Administração. São Paulo, v.1, n.3,2 sem., 1996.

NICKELS, William G. Comunicações de Marketing e Promoções. Columbus:Ohio:Grid, p.413,1976.

POFFO, Gabriela Depine. Qualidade na Percepção Dicente do Curso de Administração. 2012.

PIRES, Andréa da Silva. A percepção dos contabilistas do município de Florianópolis, com relação à implantação do sistema público de escrituração digital. 2010. 61 f. Monografia apresentada para a Universidade Federal de Santa Catarina para obtenção do grau do curso de Ciências Contábeis. Disponível em: 〈http://tcc.bu.ufsc.br/Contabeis294043>. Acesso em: 07 de setembro de 2012

SAMARA, Beatriz Santos; BARROS, Jose Carlos. Pesquisa de Marketing: conceitos e metodologia. São Paulo: Pearson Prentice Hall, 2007. 
Qualidade na percepção discente do curso de ciências contábeis na Unemat de Tangará da Serra Alexandro da Matta Sanches

Karine Medeiros Anunciato

Cleiton Franco

Marcelo Evandro Alves 